IZA DP No. 7536

Gender Differences in Cognition in China and Reasons for Change over Time: Evidence from CHARLS

Xiaoyan Lei

James P. Smith

Xiaoting Sun

Yaohui Zhao

July 2013 


\title{
Gender Differences in Cognition in China and Reasons for Change over Time: Evidence from CHARLS
}

\author{
Xiaoyan Lei \\ CCER and IZA \\ James P. Smith \\ RAND Corporation and IZA \\ Xiaoting Sun \\ CCER \\ Yaohui Zhao \\ CCER and IZA
}

Discussion Paper No. 7536

July 2013

IZA

P.O. Box 7240

53072 Bonn

Germany

Phone: +49-228-3894-0

Fax: +49-228-3894-180

E-mail: iza@iza.org

Any opinions expressed here are those of the author(s) and not those of IZA. Research published in this series may include views on policy, but the institute itself takes no institutional policy positions. The IZA research network is committed to the IZA Guiding Principles of Research Integrity.

The Institute for the Study of Labor (IZA) in Bonn is a local and virtual international research center and a place of communication between science, politics and business. IZA is an independent nonprofit organization supported by Deutsche Post Foundation. The center is associated with the University of Bonn and offers a stimulating research environment through its international network, workshops and conferences, data service, project support, research visits and doctoral program. IZA engages in (i) original and internationally competitive research in all fields of labor economics, (ii) development of policy concepts, and (iii) dissemination of research results and concepts to the interested public.

IZA Discussion Papers often represent preliminary work and are circulated to encourage discussion. Citation of such a paper should account for its provisional character. A revised version may be available directly from the author. 


\section{ABSTRACT \\ Gender Differences in Cognition in China and Reasons for Change over Time: Evidence from CHARLS ${ }^{*}$}

In this paper, we model gender differences in cognitive ability in China using a new sample of middle-aged and older Chinese respondents. Modeled after the American Health and Retirement Survey (HRS), CHARLS respondents are 45 years and older and are nationally representative of the Chinese population in this age span. Our measures of cognition in CHARLS relies on two measures that proxy for different dimensions of adult cognition episodic memory and intact mental status. We relate these cognitive measures to adult health and SES outcomes during the adult years. We find large cognitive differences to the detriment of women that were mitigated by large gender differences in education among these generations of Chinese people. These gender differences in cognition are especially concentrated in the older age groups and poorer communities within the sample. We also investigated historical, geographical, and cultural characteristics of communities to understand how they impact cognition. Economic development and environmental improvement such as having electricity, increase in wage per capita and green coverage ratio generally contribute to higher cognition ability. Women benefit more from the fruits of development - electricity and growth of green coverage ratio are conducive to lessening female disadvantage in cognition.

JEL Classification: $\quad \mathrm{H} 10$

Keywords: China, cognition

Corresponding author:

James P. Smith

RAND Corporation

1776 Main Street

PO Box 2138

Santa Monica, CA 90407

USA

E-mail: smith@rand.org

\footnotetext{
* This research was supported by grants from the National Institute on Aging and Natural Science Foundation of China.
} 


\section{Introduction}

Cognitive skills are important for many decisions including those that involve health and financial outcomes. This may be especially true for older populations in a country such as China where individuals often have to make important life decisions without the aid of professionals specializing on those topics and where levels of cognitive ability are not high. This may be particularly so for Chinese women who often outlive their husbands and will then have to start making these decisions on their own. Largely due to the absence of relevant data for China, the importance of cognitive skills for older populations in China has until recently received little scholarly attention. ${ }^{1}$

In traditional low-income environments such as rural China, families may emphasize development of human capital skills broadly defined in favor of sons at the expense of daughters. This appears to be the case with standard measures of human capital such as schooling where large gender gaps in schooling exist in low-income settings (Parish and Willis, 1993). As percapita incomes increase and education expands, education growth is much stronger for women than for men so that gender disparities appear to begin to dissipate (Becker et al., 2010). In this paper, we investigate whether these gender disparities extend ever deeper to basic cognitive skills and how gender disparities in cognition change as economic development improves over time.

In this research, we use a new data source-the Chinese Health and Retirement Longitudinal Survey (CHARLS) — that is nationally representative of those ages 45 and over in the Chinese population in 2011. This data contain detailed demographic, health, economic and

\footnotetext{
${ }^{1}$ In a previous paper (Lei et al., 2011), we examined these cognition issues using the CHARLS pilot sample that only included people in two very distinct Chinese provinces-Zhejiang and Gansu.
} 
cognitive information on individuals and families who are part of the study. CHARLS also contains contemporaneous and historical information on the communities in which CHARLS respondents live. Many of the attributes of these communities may be related to the cognitive abilities of their older residents.

This paper is divided into five sections. The next section describes the baseline CHARLS and the main cognition variables that will be used in our analysis. Section 3 outlines statistical models estimated at understanding the underlying reasons for gender differences in cognition in the Chinese context. Our main empirical findings relating individual and community level attributes to the cognitive ability of male and female respondents are in Section 4. The final section highlights our main conclusions.

\section{Material and Methods}

\subsection{Data-CHARLS}

The China Health and Longitudinal Study (CHARLS) is a nationally representative longitudinal survey of the middle-aged and elderly population (45+) in China along with their spouses, which includes an assessment of the social, economic, and health circumstances of community-residents. ${ }^{2}$ The ultimate purpose of CHARLS is to study the main health and economic adjustments to rapid population aging in China. The national baseline survey of CHARLS was conducted between June 2011 and March 2012 on 17,692 respondents. CHARLS respondents will be followed every two years using a face-to-face CAPI interview. CHARLS has been harmonized with leading international research studies in the Health and Retirement model (HRS) to ensure adoption of best practice and international comparability of results.

\footnotetext{
${ }^{2}$ For a detailed description of the CHARLS survey, see Zhao et al., 2012, "Cohort Profile: The China Health and Retirement Longitudinal Study,” International Journal of Epidemiology, forthcoming. Epublished ahead of print December 12, 2012: http://ije.oxfordjournals.org/content/early/2012/12/12/ije.dys203.long
} 
CHARLS baseline data includes detailed information of respondents and their living spouses. The CHARLS main questionnaire includes information on basic demographics, family, health status, health care, employment, and household economy (income, consumption and wealth). All data are collected by face-to-face, computer-aided personal interviews (CAPI).

The main adult outcome variables include key adult health and SES outcomes. Adult health includes self-reported general health status, doctor diagnoses of chronic illnesses, depression, word recall, lifestyle and health behaviors (physical activities, smoking, drinking), subjective expectation of mortality, activities of daily living (ADLs), and instrumental activities of daily living (IADLs). Some health variables, such as weight and height, are obtained from health measurements conducted in the field.

Financial dimensions of SES in CHARLS are measured in terms of income, wealth, and consumption expenditure. CHARLS separately measures income and assets at the individual level as well as at the household level. CHARLS income components include wage income, selfemployment income, agricultural income, pension income and transfer income, where wage income is collected for each of the household members, and transfer income separates government transfers specific to individuals from those to households.

Asset measurements collected at household level include housing, fixed assets, durables and land. Information on ownership status, value and characteristics of current residence, as well as other housing owned by the household, are recorded. Deposits and other investments are measured at the individual level, but debts are asked both for respondent and spouse, and for the household.

Household expenditures are collected in CHARLS since the literature has shown that expenditure can be a better welfare measure than income in developing countries (Strauss and 
Thomas, 2008). Consumption items are collected at weekly, monthly, and yearly frequencies respectively to minimize recall bias. Food expenditure is collected on weekly basis. It includes expenditures on dining out, food bought from market, and values of home-produced food consumed. Food expenditures induced by inviting guests for important events are collected to better reflect household food expenditure per capita in a normal week. Monthly-based expenditures are those usually spent each month, including fees for utilities, nannies, communications, etc. Yearly-based items record expenditures occurred occasionally in a year, including traveling, expenditures on durables, and education and training fees.

\subsection{Measurement in CHARLS—cognition}

Based on similar measures in HRS, there are two cognition measures used in this research. The first is memory recall based on a respondent's ability to immediately repeat in any order ten Chinese nouns just read to them (immediate word recall) and to recall the same list of words four minutes later (delayed recall). Following McArdle et al. (2007) and Lei et al. (2012), we form an episodic memory measure as the average of immediate and delayed recall scores. Episodic memory is a necessary component of reasoning in all dimensions. Our second cognitive measure is based on some components of the mental status questions of the Telephone Interview of Cognitive Status (TICS) battery established to capture intactness or mental status of individuals. In CHARLS, mental status questions include the following items—serial 7 subtraction from 100 (up to five times) and whether the respondent needed any explanation or used an aid such as paper and pencil, naming today's date (month, day, year, and season), the day of the week, and ability to redraw a picture shown to respondents. Answers to these questions are aggregated into a single mental status score that ranges from 0 to 11 . 
Table 1 presents mean levels of our two measures of cognitive ability separately for Chinese men and women stratified by age using samples of those providing their own responses. ${ }^{3}$ Across all ages, Chinese men remember about two-tenths of a word more than their female counterparts-a differential in favor of men that exists in all age groups in this table. The male cognitive advantage is even larger for intact mental status where Chinese men achieve a score more than a full point above that of Chinese women.

For both men and women, each cognitive measure declines sharply with age, a decline likely a combination of cohort and aging effects. Prior research has suggested strong normative age declines in most cognitive functions reflecting different aspects of adult cognitive profiles (Levy, 1994; McArdle et al., 2002). In a country such as China which has experienced rapid economic development during the last thirty years with impressive increases in schooling for each new generation, one would also anticipate significant cohort effects in cognition. We come back to this issue of cohort and aging effects below. There is a strong indication for both mental intactness and episodic memory of smaller gender differences among younger cohorts in Table 1, suggesting that there may be gender differential cohort or aging effects or both on cognition.

\subsection{Education}

An important dimension of socioeconomic status (SES) in any cognition analysis is education, which is well known to be directly associated with increased cognitive ability in several dimensions (McArdle and Woodcock, 1998). Education is obtained from the survey

\footnotetext{
${ }^{3}$ Sample sizes in Table 1 and subsequent analysis tables are smaller than for the full CHARLS samples because respondents moved since their time and place of birth (2,350 observations), they were less than 45 years old (206 observations), or there were missing values on our two cognition variables (2075 observations). We re-estimated our models in Tables 4 and 5 below including those who moved since birth and those less than age 45 and obtained essentially found the same results as those presented in Tables 4 and 5. In addition, the third and sixth models in Table 4 lose about 1,800 observations since height was not measured for these respondents. Once again, this deletion does not appear to affect the results significantly.
} 
question, "What is the highest level of school you have completed?" Twelve possible answers were categorized into five mutually exclusive groups: 1) "Illiterate," those who can neither read nor write; 2) "Sishu/home school or below," including those who did not finish primary school but were capable of reading or writing, or those who were reported to have been in "Sishu"4; 3) "Finished elementary school," those who have completed a primary school education; 4) "Middle school," those who have completed a middle school level education; and 5) "High and above," those who have completed a high school, vocational school, college, or graduate level education.

Using these categories, Table 2 reports distributions of education by gender and age in CHARLS baseline data. The educational level for older Chinese respondents is generally quite low with very large gender disparities particularly among the oldest cohorts. Within the 45 years and older Chinese population, there have also been impressive improvements over time in education accomplishments especially for women. Eighty percent of women over age 74 are illiterate compared to $40 \%$ of men in that age group. If we look instead at the youngest age group in Table 2 (those 45-54 years old), one in every five women is illiterate compared to 5 percent of the men. Education declines with age, but men have higher education levels than women in all age groups. Although both men and women have become more educated over time, a significant gender discrepancy still exists that is becoming smaller in the youngest cohorts compared to the oldest cohorts in Table 2. Using the 2006 Chinese Census, Lei et al. (2012) show that these education disparities have essentially disappeared among young Chinese adults, an indication of the impressive narrowing of education disparities by gender in China over time.

\footnotetext{
${ }^{4}$ Sishu is an old, private Chinese education style that before the 20th century taught young children reading, writing, and other fundamental skills.
} 


\subsection{Cognition and communities}

Especially in rural China, communities are important social and economic entities that have significant impacts on their residents. (Strauss et al., 2011 and Smith et al., 2012) find that for many health outcomes unmeasured community effects are highly important, much more so than one usually finds in other countries. Why communities are so central to understanding China is a key question and answers may depend on the specific life outcome that is examined. In terms of sex discrimination, where Chinese rural villages are close-knit communities where residents inherit, preserve, and then pass on the same culture across generations, girls may not be treated similarly relative to boys based on village attributes. These community traits may impact cognitive ability of resident girls and boys and eventually those of women and men. To obtain an initial look at economic attributes of communities, we divided all communities in the CHARLS survey into ten groups based on the community average log PCE where mean community log PCE was defined for each CHARLS respondent excluding the individual respondents' own family log PCE.

Table 3 documents for each of the ten community groups ( 1 indicates poorest and 10 richest) average mental intactness and episodic memory scores for women and men separately alongside gender difference in scores. Statistical tests are provided to indicate statistical significance of the gender difference. As the average community log PCE increases, cognitive scores of its residents increase sharply for both men and women, but this increase is far more dramatic for Chinese women compared to Chinese men. Chinese male cognitive ability also rises as communities become better off economically but nowhere near as much as for women. In the poorest set of Chinese communities, the female deficit in mental intactness is about 4 units and in episodic memory it is 2 more remembered words. These female cognitive deficits decline as 
we move into better off communities although there is actually a small female cognitive bonus to Chinese women in the richest set of communities.

The last three set of columns in Table 3 show fractions of women and men in these ten community groups who are illiterate with the final column tallying female-male difference in illiteracy rates. In the poorest set of communities, over $60 \%$ of female residents over age 45 are illiterate compared to $24 \%$ of men. While female rates of illiteracy exceed male rates in all ten groups, gender difference become much smaller as we reach the richest group of communities.

The level of economic activity of the community in which you live should most likely be thought of as a summary statistic for the underlying reasons why communities matter so much for cognition. There are many other aspects of the community that may matter for cognition, some of which are included in the CHARLS survey. In this research in addition to the level of

economic resources in the community, these will include community Social Activities, years of electricity available, measures of the remoteness of the community, years of people's commune, the presence of common surnames in the community, and the amount of economic growth experienced in the community.

\subsubsection{Social activities}

Social Activities in CHARLS include participating in one of the following activities: 1) volunteer or charity work; 2) caring for a sick or disabled adult who does not live with the respondent and who does not pay for the help; 3) attending an educational or training course; 4) interacting with friends; 5) playing Mahjong, chess, or cards, or going to a community club; 6) attending a sporting event or other kind of club; 7) taking part in a community related organization;

Social activities play an important role in the daily life of most Chinese elderly. We 
define a variable called "any social activity" to indicate if a respondent was involved in at least one social activity. In aggregate, 44 percent of the sample participated in at least one of the social activities. Social activity may benefit cognitive functioning of the elderly by providing resistance to mental diseases, such as dementia and by reducing rates of cognitive decline (Hu, 2012; Wang et al., 2002). If men and women participate in social activities with different intensity or of different stimulating capability, the effect of social activity on cognition may be different by gender.

\subsubsection{Years of electricity available}

The community questionnaire asks when electricity was first available in the village. The variable-years of electricity available-is constructed using this information. Urban areas in general had electricity available a long time ago so it is difficult for the current urban residents to know exactly the timing of the community. Therefore, the survey only asks this question in rural areas. In the paper, we use the value of the 95 percentile of rural villages for urban communities. This is reasonable as the starting time of electricity in urban areas is in general homogenous and long ago.

Electricity contributes to people's acquisition of knowledge and improvement of education quality. Women may be more sensitive to the benefit of electricity than men at least for the following two reasons. Firstly, electricity facilitates study and reading and therefore increases cognitive abilities. Given the level of education completed, the quality of study may be better in areas with electricity. If women spend more time at home and are more likely to study by themselves, electricity will contribute to smaller gender difference in cognition. Second, in areas where electricity is available, people can obtain more information and knowledge through TV, which may be cognitively stimulating. Availability of electricity may 
benefit women more as watching TV is the main (if not the only) source for them to obtain information and knowledge about the outside world, especially for those rural women whose activities are mostly around the home. Unlike other sources of knowledge, electricity generated information flows may be more akin to a public good in which it is more difficult to exclude women.

\subsubsection{Mountainous region}

We use terrain as a proxy for geographical isolation. The community questionnaire asks the main terrain/topography of the village /community with options being "plain," "hill," “mountainous region,” and “others.” We create a dummy variable-mountainous region that have a value of 1 if the answer is "mountainous region" and 0 if otherwise. We expect that this variable may have a negative effect on cognition as geographical isolation may prevent people from communicating with and obtaining information from outside the community. Women may be more restricted by this isolation environment as it is physically more difficult for them to overcome this obstacle.

\subsubsection{Years of people's commune}

The people's commune or the namely "big pot" was the highest of the three administrative levels (commune, production brigades and production teams) in rural China during the period of 1954 to 1985 until they were replaced by townships. In the commune, everything was shared, all resources were controlled and all farming activities were centrally assigned. The commune has been blamed for failing to raise peasant income and to provide incentives for peasants to work harder. This in turn has made it difficult for many communes to accumulate funds to invest in diversification and sideline activities to further modernization, or to provide welfare services (O'Leary and Watson, 1982), which may 
adversely impact people's health status as well as cognitive abilities. During the period of commune, people largely live with hunger which may in turn undermine cognitive ability. Therefore, the longer the existence of a commune, the more likely is the cognitive disadvantage of people (Tamas and Karagianis, 2006)

The CHARLS questionnaire has information for each village on when the commune was founded and when it was disintegrated, so we construct a variable on how long local people's commune lasted. Since the community data may be subject to recall error, we set cutoffs to the starting and ending year of people's commune. Communes were founded during the period of 1954-1960, so 1954 was imputed if the reported founding time was before 1954 and 1960 was used if it was after 1960. Similarly, as the disintegrating year of people's commune should be between 1978 and 1985, these two cutoff points were used for the outliers. Length of commune was then defined as the difference between ending year and starting year. As commune was only a rural phenomenon, 0 was used for urban communities. Intuitively, length of commune may be negatively correlated with cognition.

\subsubsection{Big surname}

Villages are asked whether it has big surnames and if they do, the three largest surnames are asked in the questionnaire. We combine information on respondent's surname and the big surnames in the community to construct three dummies: (1) the village has big surnames and the respondent's surname belongs to the three biggest ones; (2) the village has big surnames but the respondent's surname does not belong to the three biggest ones; and (3) the community doesn't have big surnames. In addition, a female respondent whose husband has a big surname in the village is also assigned to the first category because she shares the social and family networks of her husband. Again, as big surname is only a rural 
phenomenon, respondents in urban communities are grouped into the third category. In our empirical analysis below, we use the second category as the reference group. Big surname reflects extensive networks of personal contacts, and thus may provide more opportunity to communicate with relatives and others or to play a bigger role in community leadership, which may in turn promote cognitive functioning.

\subsubsection{Economic development}

We also exploit prefecture-level economic and environmental variables from the Chinese yearbooks (1996 to 2007) to construct local status of economic development. Economic development varies a great deal across regions and communities in China being concentrating in the Eastern coastal areas. Since a higher growth rate might be accompanied by a lower initial level, we use both growth rates and initial levels of development to depict a fuller picture of the level of economic development and how it has been changing over time. Four measures were constructed for this research: average annual growth rate of green coverage ratio from 1997 to 2003, average annual growth rate of wage per capita from 1996 to 2007, green coverage ratio in 1996, and wage per capita (thousand) in 1995. Green coverage ratio is defined as the ratio of the green areas to a certain ground, reflects local willingness to protect the environment, improve welfare, and pursue sustainable development. Green areas play a crucial role in producing oxygen and purifying the air, which may be beneficial to people's health and cognitive abilities. Wage per capita and its growth rate are indicators of local economic development and the resources available for people to raise their welfare that may lead to higher cognitive ability. 


\section{Statistical Models for Estimating Gender Differences in Cognition}

We use three main specifications to analyze underlying reasons for gender difference in cognition among elderly in China. Our main focus is whether personal attributes, community characteristics and local status of economic and environmental development influence cognition of older residents and whether these effects differ by gender.

Our baseline models take only personal attributes into consideration and examine the factors that may impact gender difference:

$$
\operatorname{Cog}_{i}=\beta_{0}+\beta_{1} \text { Fem }_{i}+\beta_{2} X_{i}+\alpha_{p}+\varepsilon_{i}
$$

where $\operatorname{Cog}_{i p}$ is the measure of cognitive ability of person $i$-mental intactness or episodic memory. $\mathrm{Fem}_{i}$ is the variable of interest, which takes a value of 1 if the respondent is a female and 0 otherwise. $X_{i}$ is a set of personal attributes variables including age minus 45 and its squared term, urban dummy, log (Height) and socioeconomic status measured by education and log of household per capita expenditure (log PCE). Province fixed effect is controlled by $\alpha_{p}$ in all the baseline analyses. $\varepsilon_{i}$ is the error term.

In our second specification shown below, community variables are included to investigate whether the history and economic development of local community would significantly influence the cognition of the elderly residents and whether the effects differ by gender:

$$
\operatorname{Cog}_{i}=\beta_{0}+\beta_{1} \text { Fem }_{i}+\beta_{2} X_{i}+\beta_{3} Z_{c}+\beta_{4} Z_{c} * F_{e m}+\alpha_{p r}+\varepsilon_{i}
$$

Where $Z_{c}$ refers to community variables. We first add the log PCE of the community only, which was defined above in Section 2. We then investigate additional community variables to depict the historical, geographical and cultural characteristics of the community such as years of electricity available, years of people's commune, mountainous region, and big surname. 
Social activity variables are also included as these activities reflect interactions of the respondent with other people, most likely those living in the same community. The introduction of these community variables can be found in Section 2. The interaction terms of the community variables and gender dummy, $Z_{c} * F e m_{i}$, are included in this model to examine whether men and women are impacted differently by community factors. Instead of province, we control for prefecture fixed effects, $\alpha_{p r}$, in the second specification, which belongs to an administrative level between county and province.

Our third specification sheds light on how development of economy and environment can affect cognition of people:

$$
\operatorname{Cog}_{i}=\beta_{0}+\beta_{1} F_{e m}+\beta_{2} X_{i}+\beta_{3} Z_{c}+\beta_{4} Z_{c} * F_{e m}+\beta_{5} E_{p r}+\beta_{6} E_{p r} * F_{e m}+\alpha_{p}+\varepsilon_{i}
$$

As described in Section 2, four measures were constructed: average prefecture annual growth rate of green coverage ratio from 1997 through 2003, average annual growth rate of wage per capita from 1996 through 2007, green coverage ratio of 1996, and wage per capita (thousand) of 1995. As these development measures are all at the prefecture level, we turn to province fixed effects in this specification.

\section{Empirical Findings}

\subsection{The Effects of Personal Attributes}

Our baseline analysis for personal attributes related to both our measures of cognitionmental intactness and episodic memory—are presented in Table 4. The first model for each cognitive outcome in columns 1 and 4 include only a quadratic in age ${ }^{5}$, a dummy variable for being a woman. Not surprisingly for both cohort and life cycle aging reasons, both cognitive variables decrease with age at an increasing rate. The negative coefficient on female indicates

\footnotetext{
${ }^{5}$ In these models age is defined as age -45 to ease interpretation of the trajectories implied by the age quadratic.
} 
that on average women are at a cognitive disadvantage compared to men, an effect that increases with age (or decreases among more recent cohorts). These female coefficients are quite similar in magnitude to the unadjusted differences by sex in Table 1.

The second model for both cognitive outcomes is listed in columns 2 and 5 of Table 4. In these models, we add dummy variables for the education categories used in Table 2. We also include a full set of Province dummies in which the respondent lived—our first albeit very aggregate measure of the community in which one lived. The effects of education on both cognitive measures are quite dramatic as there is a continuous and large increase in cognitive ability as schooling levels rise. Compared to those respondents who are illiterate, those who at least finished high school increase their mental intactness by 3.3 units and remember 1.7 more words on average. Including a measure of education, increases the $\mathrm{R}^{2}$ by three fold for our measure of mental intactness and by more than double for episodic memory, a good indication of the explanatory power of education for cognitive ability.

Including our measure of education significantly reduces the female disparity in mental intactness from 1.17 to 0.34 . Similarly, the female cognitive deficit for episodic memory of 0.25 is completely eliminated and we now find an advantage (statistically significant advantage of 0.127) for Chinese women compared to Chinese men once we compare people with the same education. A significant part of the Chinese female disparity in cognition is therefore due to their historically low levels of education compared to Chinese men. On a more positive note, the rapidly improving cognitive ability of Chinese women compared to Chinese men over time is again largely due to their improving levels of schooling compared to Chinese men.

The third column in Table 4 for each cognitive outcome (columns 3 and 6) adds three measures to these models - urban residence, log height, and the log PCE of the household, our 
best measure of the economic resources of the household in a developing country such as China. Not surprisingly, those living in urban areas have statistically significantly higher cognitive ability in both mental intactness and episodic memory. Taller people also have higher cognitive levels which may be because that height is an indicator of better health resulting from better nutrition in childhood. Higher levels of household log PCE also are associated with higher cognitive ability in both our cognitive measures. Including these three additional personal attributes further reduces the female deficit in mental intactness which also remains statistically significant and further increases their cognitive advantage in episodic memory.

\subsection{The effects of community resources}

In this subsection, we investigate aspects of community that may matter for the cognitive ability of their residents, both men and women. Our first community measure is the log PCE in the community which is calculated for each respondent as the mean of the natural log household PCE of all residents of the community with the exception of the particular respondent in question. This allows us to separate out effects of the resources directly available to the household (log household PCE) and the average resources of the community (log community PCE). In all our community models presented in this section, we also include a set of Prefecture dummies to control for any other unobserved geographic factors. Prefectures are administrative units that govern a combination of counties in China. There are 127 prefectures in our CHARLS data so that prefectures offer a more precise control for other unmeasured factors related to place of residence than the more aggregated Province level dummy variable does.

Our results are presented in Table 5 for our two cognition measures. For each measure, we present two models. In addition to our demographic and SES education variables, the first

model contains measures of log PCE both at the household and community level as explained 
above. The second model for each cognitive outcome then adds an interaction of being female with both Log PCE (household and community) constructs in order to assess whether their effects differ by sex.

For both cognitive outcomes, we find statistically significant effects for community and household log PCE, but the estimated effects of the community variant is larger than it is for the household variant at least for the Mental Intactness measure. When we next examine the female interaction model, we find that the effects of higher level of community resources in improving cognition are stronger for Chinese women than for Chinese men, although this improvement is only significant for mental intactness.

\subsection{The effects of community attributes on cognition}

In order to understand other possible dimensions of community level effects, we next add more community variables to the models. These results are contained in Table 6. The first model reported under each outcome adds the main effects of these new community level attributes while the second model also adds the interaction of these new community level attributes with being female.

As described above, "any social activities," “years of electricity available,” "mountainous region,” "years of commune,” and dummy variables for big surname are included in Columns 1

and 3 of Table 6. As expected, participating in social activities positively associates with both cognitive measures in all models. When we separated 'social activities' into their sub-component parts, the two that were most positively associated with cognition were 'playing Ma-jong, chess or other card games' and 'other social activities'. As discussed extensively in Lei et al (2012) using the Pilot data for CHARLS, this estimate reflects an association and it is not a causal estimate. Individuals who engage in such social activities may do so since they are more 
cognitively intact to begin with especially in the age range of the CHARLS sample. Finding good instruments to deal with this problem is not straightforward.

As expected, years of electricity availability significantly correlates positively with mental intactness, but not for episodic memory while existing length of time spent in a commune is negatively associated with both our cognitive measures.

Living in a mountainous region negatively correlates with mental intactness, but as somewhat of a puzzle positively does so for episodic memory. For big surname variables, the reference group is that the community has common surnames but the individual respondent does not have one of these surnames. Compared to that situation, the only significant effect is advantage of mental intactness of people in a community without any surname. This may indicate that those communities without any big surnames may be more diverse and more mobile across people and therefore do not limit their activities along a family tie.

With the exception of 'social activities' which can and do vary between the genders, the other community level variables in the models in Table 6 and Table 7 are common shared experiences of those who live in these community. Therefore, for these variables to have differential effects on the cognitive ability of women compared to Chinese men the impacts of these community attributes on cognition must differ between men and women. With this in mind, we next added the interactions of these community variables with a female dummy in the regressions of Columns 2 and 4 in Table 6. The results show that electricity availability not only promotes mental intactness, but also shrinks the gender disparity in mental intactness. Similarly, it is a cognitive advantage for women without a common surname (either hers or her partner) to live in community without these common surnames as opposed to living a community with common surnames when she does not. The latter situation may lead to social isolation. 


\subsection{The effects of economic and environmental development}

The last set of models we use includes the two community level measures of economic growth and development — the growth rate of green coverage ratio 1997-2003 and the growth rate of wage per capita 1996-2007 while simultaneously controlling for the two initial level of each. At least in this version of the paper, we have not added models with both community attributes as well as community growth rates.

As seen from Columns 1 and 3 of Table 7, the two growth rates both positively correlate with mental intactness, but the associations of these two measures with episodic memory is opposite, positive for growth rate of green overage ratio but negative for wage growth rate. The two initial levels both positively correlate with the two cognitive measures. It seems that economic and environmental status benefit cognitive ability, but the growth rate does not necessarily do so. The growth of economy may hurt cognitive ability measured by episodic memory, while improvement of environment is always beneficial.

Columns 2 and 4 present the results adding the interaction terms of these measures with female dummy. Consistent with the evidence we presented above, we do not find strong estimates of gender differences in these effects.

\section{Conclusions}

In this paper, we examined the size and determinants of gender differences in cognition among those 45 and over in China. We rely on an important recent data source-China Health and Retirement Longitudinal Study (CHARLS) 2011-12 baseline data-that is part of the international network of Health and Retirement Surveys (HRS) around the world. We find large cognitive differences to the detriment of women that are considerably larger within older cohorts 
of our sample. These cognitive disparities are considerably mitigated but not fully explained by large gender differences in education among these generations of Chinese people.

These gender differences in cognition are also concentrated within and related to the poorer communities in China with the gender differences being more sensitive to community level attributes than to family level attributes, with economic resources (measured by per capita expenditures) being the primary illustration of that point. In traditional poor Chinese communities, there are strong economic incentives to favor boys at the expense of girls not only in their education outcomes, but in their nutrition and eventually their adult height. We also find that these gender differences in cognitive ability have been steadily decreasing across birth cohorts as the economy of China grew rapidly. Among younger cohorts of young adults in China, there is no longer any gender disparity in cognitive ability perhaps suggesting that with continued economic development China will move toward the American case where cognitive skills of women are at least equal of those of men.

We also investigated the historical, geographical, and cultural characteristics of communities as well as levels and growth rates of economic and environmental development to understand how they impact cognition. Evidence is found that economic development and environmental improvement such as having electricity, increase in wage per capita and green coverage ratio generally contribute to higher cognition ability. Women benefit more from the fruits of development -electricity and growth of green coverage ratio are conducive to lessening female disadvantage in cognition. People living in communities with no big surnames have higher cognitive abilities, which may be due to higher mobility of these communities. We find that people's commune is detrimental to both mental intactness and episodic memory and that the effect of living in remote mountainous regions is negative. 


\section{Acknowledgements}

This research was supported by grants from the National Institute on Aging and Natural Science Foundation of China. 


\section{References}

Becker, G.S., Hubbard, W.H.J., Murphy, K.M., 2010. Explaining the worldwide boom in higher education of women. J Hum Capital 4(3), 203-241.

Hu, Y., Lei, X., Smith, J.P., Zhao, Y., 2012. Effects of social activities on cognitive function: Evidence from CHARLS, in: Smith, J.P., Majmundar, M. (Eds.), Aging in Asia: Findings from New and Emerging Data Initiatives. National Academy of Sciences Washington, DC, pp.279303

Lei, X., Hu, Y., Smith, J.P., Zhao, Y., 2012. Gender differences in cognition among older adults in China. J Hum Resour. 47, 951-971.

Levy, R., 1994. Aging-associated cognitive decline. Int Psychoger 6(1), 63-68.

McArdle, J.J., Fisher, G.G., Kadlec, K.M., 2007. Latent variable analysis of age trends in tests of cognitive ability in the Health and Retirement Survey, 1992-2004. Psychol Aging 22(3), 525-545.

McArdle, J.J., Ferrer-Caja, E., Hamagami, F., Woodcock, R.W., 2002. Comparative longitudinal structural analyses of the growth and decline of multiple intellectual abilities over the life span. Dev Psychol. 38(1), 115-42.

McArdle, J.J., Woodcock, R.W. (eds.), 1998. Human Abilities in Theory and Practice. Lawrence Erlbaum Associates, New Jersey.

O'Leary, G., Watson, A., 1982. The production responsibility system and the future of collective farming. Aust J Chinese Aff 8, 1-34.

Parish, W., Willis, R.J., 1993. Daughters, education, and family budgets Taiwan experiences. J Hum Resour. 28(4), 863-889.

Smith, J.P, Shen, Y., Strauss, J, Zhe, Y, and Zhao, Y., 2012. The effects of childhood health on adult health and SES in China. Econ Dev Cult Change 61(1), 127-156.

Strauss, J., Lei, X., Park, A., Shen, Y., Smith, J. P., Zhe, Y., Zhao, Y., 2011. Health outcomes and socio-economic status among the elderly in China: Evidence from the CHARLS Pilot. J Popul Ageing 3(3-4), 111-142.

Treuer, T., Karagianis, J., 2006. Is hunger a driver of the cognitive development? Neuropsychopharmacology 31, 2326-2327.

Wang, H.X., Karp, A., Winblad, B., Fratiglioni, L., 2002. Decreased risk of dementia: A longitudinal study from the Kungsholmen Project. Am J Epidemiol. 155(12), 1081-1087. 
Zhao, Y., Hu, Y., Smith, J.P., Strauss J, Yang, G., 2012. Cohort profile: The China Health and Retirement Longitudinal Study. Forthcoming in Int J Epidemiol. Epublished ahead of print December 12, 2012:

http://ije.oxfordjournals.org/content/early/2012/12/12/ije.dys203.full.pdf 
Table 1. Gender Difference in Cognitive Function (weighted): by Age

\begin{tabular}{|c|c|c|c|c|c|c|c|c|c|c|}
\hline \multirow[b]{2}{*}{ Ages } & \multicolumn{5}{|c|}{ Mental Intactness } & \multicolumn{5}{|c|}{ Episodic Memory } \\
\hline & Number & Overall & Female & Male & Difference & Number & Overall & Female & Male & Difference \\
\hline $45-49$ & 2,715 & 8.991 & 8.686 & 9.382 & $-0.697 * * *$ & 2,740 & 3.953 & 3.929 & 3.987 & -0.059 \\
\hline $50-54$ & 1,997 & 8.647 & 8.295 & 9.013 & $-0.718 * * *$ & 2,011 & 3.548 & 3.530 & 3.567 & -0.037 \\
\hline $55-59$ & 2,751 & 8.386 & 7.802 & 8.973 & $-1.171 * * *$ & 2,756 & 3.355 & 3.213 & 3.497 & $-0.284 * * *$ \\
\hline $60-64$ & 2,250 & 8.286 & 7.721 & 8.814 & $-1.092 * * *$ & 2,267 & 3.223 & 3.091 & 3.349 & $-0.257 * * *$ \\
\hline $65-74$ & 2,428 & 7.77 & 6.976 & 8.441 & $-1.466 * * *$ & 2,427 & 2.83 & 2.64 & 2.993 & $-0.353^{* * *}$ \\
\hline $75+$ & 920 & 6.505 & 5.784 & 7.273 & $-1.489 * * *$ & 930 & 1.795 & 1.58 & 2.039 & $-0.459 * * *$ \\
\hline All & 13,061 & 8.283 & 7.782 & 8.795 & $-1.013^{* * *}$ & 13,131 & 3.275 & 3.185 & 3.369 & $-0.184 * * *$ \\
\hline
\end{tabular}

Source: CHARLS 2011 Baseline Data. Difference is Female - Male. Number is number of observations. Statistically significant at $1 \%(* * *) 5 \%(* *)$ and 10\% (*) level. 
Table 2. Education: Fraction in each schooling group by Gender and Age Groups (weighted)

\begin{tabular}{|c|c|c|c|c|c|c|c|c|c|c|c|}
\hline \multirow[b]{2}{*}{ Education Participation Rate } & \multirow[t]{2}{*}{ All } & \multicolumn{5}{|c|}{ Female } & \multicolumn{5}{|c|}{ Male } \\
\hline & & All & $45 \sim 55$ & $55 \sim 65$ & $65 \sim 75$ & $\begin{array}{l}75 \text { and } \\
\text { above }\end{array}$ & All & $45 \sim 55$ & $55 \sim 65$ & $65 \sim 75$ & $\begin{array}{l}75 \text { and } \\
\text { above }\end{array}$ \\
\hline Illiterate & 0.263 & 0.400 & 0.218 & 0.421 & 0.543 & 0.795 & 0.127 & 0.047 & 0.113 & 0.189 & 0.398 \\
\hline Sishu/home school and below & 0.179 & 0.176 & 0.147 & 0.231 & 0.165 & 0.109 & 0.182 & 0.115 & 0.223 & 0.196 & 0.257 \\
\hline Elementary school & 0.212 & 0.165 & 0.188 & 0.162 & 0.184 & 0.055 & 0.259 & 0.197 & 0.292 & 0.335 & 0.202 \\
\hline Middle school & 0.213 & 0.161 & 0.264 & 0.124 & 0.083 & 0.014 & 0.265 & 0.381 & 0.247 & 0.162 & 0.08 \\
\hline High school and above & 0.131 & 0.096 & 0.181 & 0.059 & 0.023 & 0.015 & 0.166 & 0.259 & 0.124 & 0.116 & 0.056 \\
\hline Observations & 14033 & 6961 & 2660 & 2602 & 1145 & 553 & 7069 & 2460 & 2702 & 1382 & 524 \\
\hline
\end{tabular}

Source: CHARLS 2011 Baseline Data. 
Table 3. Cognition by Log PCE in Community (weighted)

\begin{tabular}{|c|c|c|c|c|c|c|c|c|c|c|c|c|}
\hline \multirow[b]{2}{*}{$\begin{array}{l}\text { Mean Log } \\
\text { PCE in } \\
\text { Community }\end{array}$} & \multicolumn{4}{|c|}{ Mental Intactness (0-10) } & \multicolumn{4}{|c|}{ Episodic Memory } & \multicolumn{3}{|c|}{ Fraction Illiterate } & \multirow[b]{2}{*}{$\begin{array}{c}\text { Female- } \\
\text { Male }\end{array}$} \\
\hline & $\mathrm{N}$ & Female & Male & $\begin{array}{c}\text { Female- } \\
\text { Male }\end{array}$ & $\mathrm{N}$ & Female & Male & $\begin{array}{c}\text { Female- } \\
\text { Male }\end{array}$ & $\mathrm{N}$ & Female & Male & \\
\hline 7.898 & 1448 & 6.713 & 8.015 & $-1.302 * * *$ & 1444 & 2.868 & 3.149 & $-0.281 * * *$ & 1725 & 0.606 & 0.237 & $0.369 * * *$ \\
\hline 8.192 & 1384 & 6.985 & 8.416 & $-1.430 * * *$ & 1398 & 2.668 & 3.186 & $-0.518 * * *$ & 1625 & 0.512 & 0.158 & $0.354 * * *$ \\
\hline 8.333 & 1435 & 7.251 & 8.51 & $-1.259 * * *$ & 1431 & 3.045 & 3.334 & $-0.289 * * *$ & 1631 & 0.522 & 0.142 & $0.380 * * *$ \\
\hline 8.449 & 1405 & 7.456 & 8.667 & $-1.212 * * *$ & 1423 & 2.996 & 3.247 & $-0.251 * *$ & 1622 & 0.453 & 0.144 & $0.310 * * *$ \\
\hline 8.546 & 1385 & 7.254 & 8.453 & $-1.199 * * *$ & 1389 & 2.798 & 3.143 & $-0.344^{* * *}$ & 1574 & 0.45 & 0.154 & $0.297 * * *$ \\
\hline 8.668 & 1380 & 7.405 & 8.491 & $-1.086 * * *$ & 1392 & 3.084 & 3.25 & -0.166 & 1551 & 0.444 & 0.129 & $0.315^{* * *}$ \\
\hline 8.827 & 1219 & 7.859 & 8.751 & $-0.892 * * *$ & 1239 & 3.016 & 3.104 & -0.087 & 1419 & 0.43 & 0.13 & $0.300 * * *$ \\
\hline 9.015 & 1072 & 8.147 & 9.189 & $-1.042 * * *$ & 1054 & 3.509 & 3.484 & 0.025 & 1225 & 0.422 & 0.125 & $0.297 * * *$ \\
\hline 9.236 & 911 & 8.601 & 9.469 & $-0.868 * * *$ & 934 & 3.666 & 3.746 & -0.080 & 1071 & 0.267 & 0.069 & $0.198 * * *$ \\
\hline 9.785 & 1101 & 9.438 & 9.908 & $-0.470 * * *$ & 1106 & 3.96 & 4.009 & -0.049 & 1271 & 0.162 & 0.043 & $0.119 * * *$ \\
\hline 8.735 & 12740 & 7.788 & 8.809 & $-1.021^{* * *}$ & 12810 & 3.202 & 3.381 & $-0.180^{* * *}$ & 14714 & 0.414 & 0.131 & $0.283^{* * *}$ \\
\hline
\end{tabular}

Communities are placed into ten groups from lowest to highest based on the mean Log PCE of all residents of those communities minus the respondent.

Statistically significant at 1\% (***) 5\% (**) and $105\left(^{*}\right)$ level. 
Table 4. Baseline OLS Analysis of Age, Gender and Education on Cognition

\begin{tabular}{|c|c|c|c|c|c|c|}
\hline \multirow{2}{*}{$\begin{array}{r}\text { Independent Variables } \\
\text { Demographics }\end{array}$} & \multicolumn{3}{|c|}{ Mental Intactness (0-11) } & \multicolumn{3}{|c|}{ Episodic Memory (0-10) } \\
\hline & (1) & (2) & (3) & (4) & (5) & (6) \\
\hline \multirow[t]{2}{*}{ Age - 45} & $-0.042 * * *$ & $0.020 * * *$ & $0.023 * * *$ & $-0.035^{* * *}$ & -0.001 & -0.001 \\
\hline & $(0.006)$ & $(0.006)$ & $(0.006)$ & $(0.005)$ & $(0.005)$ & $(0.005)$ \\
\hline \multirow[t]{2}{*}{ (Age- 45) squared } & $-0.001 * * *$ & $-0.001 * * *$ & $-0.001 * * *$ & $-0.001 * * *$ & $-0.001^{* * *}$ & $-0.001^{* * *}$ \\
\hline & $(0.000)$ & $(0.000)$ & $(0.000)$ & $(0.000)$ & $(0.000)$ & $(0.000)$ \\
\hline \multirow[t]{2}{*}{ Female } & $-1.160 * * *$ & $-0.342 * * *$ & $-0.105 *$ & $-0.245^{* * *}$ & $0.127 * * *$ & $0.172 * * *$ \\
\hline & $(0.040)$ & $(0.037)$ & $(0.056)$ & $(0.032)$ & $(0.033)$ & $(0.046)$ \\
\hline \multirow[t]{2}{*}{ Log Height } & & & $4.779 * * *$ & & & $0.963^{* *}$ \\
\hline & & & $(0.560)$ & & & $(0.432)$ \\
\hline \multirow[t]{2}{*}{ Urban } & & & $0.376^{* * *}$ & & & $0.155^{* * *}$ \\
\hline & & & $(0.044)$ & & & $(0.039)$ \\
\hline \multicolumn{7}{|c|}{ SES Education (illiterates omitted) } \\
\hline \multirow[t]{2}{*}{ Sishu/home school and below } & & $1.492 * * *$ & $1.419 * * *$ & & $0.422 * * *$ & $0.408 * * *$ \\
\hline & & $(0.061)$ & $(0.065)$ & & $(0.046)$ & $(0.049)$ \\
\hline \multirow[t]{2}{*}{ Elementary school } & & $2.284 * * *$ & $2.618^{* * *}$ & & $0.814 * * *$ & $0.761^{* * *}$ \\
\hline & & $(0.057)$ & $(0.064)$ & & $(0.046)$ & $(0.050)$ \\
\hline \multirow[t]{2}{*}{ Middle school } & & $2.852 * * *$ & $2.618^{* * *}$ & & $1.310^{* * *}$ & $1.211^{* * *}$ \\
\hline & & $(0.058)$ & $(0.064)$ & & $(0.050)$ & $(0.055)$ \\
\hline \multirow[t]{2}{*}{ High school and above } & & $3.312 * * *$ & $2.918 * * *$ & & $1.719 * * *$ & $1.647 * * *$ \\
\hline & & $(0.060)$ & $(0.070)$ & & $(0.061)$ & $(0.068)$ \\
\hline \multirow[t]{2}{*}{ Log PCE } & & & $0.216^{* * *}$ & & & $0.162 * * *$ \\
\hline & & & $(0.026)$ & & & $(0.022)$ \\
\hline Province Dummies & NO & YES & YES & NO & YES & YES \\
\hline Observations & 13,090 & 13,090 & 11,289 & 13,161 & 13,161 & 11,323 \\
\hline R-squared & 0.124 & 0.362 & 0.372 & 0.086 & 0.187 & 0.202 \\
\hline
\end{tabular}


Table 5. OLS Analysis Adding Measures of Household and Community Log PCE

Mental Intactness Episodic Memory

Independent Variables

\section{Demographics}

Age - 45

(Age- 45) squared

Female

Urban

Log Height

\section{SES}

Education(illiterate omitted)

Sishu/home school and below

Elementary school

Middle school

High school and above

Log household PCE

Community log PCE

Community log PCE*female

Log household PCE*female

Prefecture Dummies

YES

Observation

11,289

0.414

$1.419^{* * *}$

$2.134 * * *$

$2.574 * * *$

$2.830 * * *$

$0.152 * * *$

$0.323^{* * *}$

$(0.063)$

$(0.061)-2.130 * * *$

(0.064) 2.565***

(0.071) 2.823***

(0.028)

$0.175^{* * *}$

(0.065)

$0.236 * * *$

R-squared

Standard errors in parentheses.

$* * * \mathrm{p}<0.01, * * \mathrm{p}<0.05, * \mathrm{p}<0.1$
$0.170^{* *}$

$-0.044$

(2)

(3)

(4)

Episodic Memory

$\begin{array}{lllll}(0.006) & -0.005 & (0.005) & -0.005 & (0.005) \\ (0.000) & -0.001^{* * *} & (0.000) & -0.001^{* * *} & (0.000) \\ (0.588) & 0.166^{* * *} & (0.045) & -0.669 & (0.553) \\ (0.060) & 0.083 & (0.052) & 0.084 & (0.052) \\ (0.524) & 0.879^{* *} & (0.421) & 0.880^{* *} & (0.421)\end{array}$

$(0.063)$

$0.461^{* * *}$

$(0.048)$

$0.457 * * * \quad(0.048)$

$(0.061)$

$0.790^{* * *} \quad(0.048)$

$0.786 * * * \quad(0.048)$

$(0.064)$

$1.224 * * *$

$(0.054)$

$1.217^{* * *} \quad(0.054)$

$(0.071)$

$1.654^{* * *}$

$(0.067)$

$1.650 * * *$

$(0.067)$

$(0.037)$

$0.151^{* * *}$

$(0.024)$

$0.150 * * *$

$(0.076)$

0.102*

(0.060)

0.053

(0.084)

0.094

0.003

YES

YES

11,323

11,323

11,289

0.270

0.270 
Table 6. OLS Analysis Adding Measures of Community

Mental Intactness

Episodic Memory

Independent Variables

(2)

(3)

(4)

\section{Demographics}

Age - 45

(Age- 45) squared

Female

Urban

Log Height

$\underline{S E S}$

Education(illiterate omitted)

Sishu/home school and below

Elementary school

Middle school

High school and above

Log household PCE

Community log PCE

Community log PCE*female

Log household PCE*female

$\begin{array}{llllllll}0.024^{* * *} & (0.006) & 0.023^{* * *} & (0.006) & -0.004 & (0.005) & -0.004 & (0.005) \\ -0.001^{* * *} & (0.000) & -0.001^{* * *} & (0.000) & -0.001^{* * *} & (0.000) & -0.001^{* * *} & (0.000) \\ -1.349^{* *} & (0.591) & -1.102 & (0.738) & -0.775 & (0.555) & -1.099 & (0.669) \\ 0.181^{* *} & (0.073) & 0.182^{* *} & (0.073) & 0.107^{*} & (0.062) & 0.107^{*} & (0.062) \\ 3.963^{* * *} & (0.528) & 3.950^{* * *} & (0.526) & 0.670 & (0.423) & 0.672 & (0.423)\end{array}$

$1.401 * * *$

$2.118^{* * *}$

$\begin{array}{lll}(0.064) & 1.390 * * * & (0.064)\end{array}$

$0.445^{* * *}$

$(0.048)$

$0.450 * * *$

(0.049)

$2.562 * * *$

(0.062)

$2.104^{* * *} \quad(0.063)$

$0.787 * * *$

$(0.049)$

$0.792 * * *$

(0.049)

$2.801 * * *$

$(0.065)$

(0.065)

$1.216^{* * *}$

$(0.054)$

$1.222 * * *$

(0.054)

$0.155^{* * *}$

(0.038)

$2.794 * * * \quad(0.073)$

$1.629 * * *$

(0.068)

$1.635^{* * *}$

(0.068)

$0.187 * *$

(0.038)

$0.139 * * *$

$0.139 * * *$

(0.034)

$0.180 * *$

$0.224 * * *$

$(0.034)$

$-0.006$

$(0.080)$

$(0.098)$

0.014

$(0.077)$

$0.150 *$

$(0.089)$

$-0.047$

(0.055)

$-0.050$

(0.055)

$-0.002$

(0.046)

$-0.003$

$(0.047)$

\section{Community Variables}

Any Social Activities

Years of electricity available

Mountainous region

Years of commune

Big surname (reference: R no,

Community Yes)

$\mathrm{R}$ yes, Community yes

R no, Community no

$\begin{array}{llllllll}0.240^{* * *} & (0.038) & 0.238^{* * *} & (0.050) & 0.278^{* * *} & (0.033) & 0.257^{* * *} & (0.045) \\ 0.008^{* * *} & (0.003) & 0.002 & (0.004) & -0.003 & (0.003) & -0.003 & (0.003) \\ -0.290^{* * *} & (0.085) & -0.298^{* * *} & (0.097) & 0.142^{* *} & (0.072) & 0.155^{*} & (0.081) \\ -0.020^{* *} & (0.008) & -0.017^{*} & (0.009) & -0.015^{* *} & (0.007) & -0.015^{*} & (0.008) \\ & & & & & & & \\ 0.048 & (0.048) & -0.002 & (0.048) & -0.019 & (0.040) & -0.063 & (0.054) \\ 0.181^{* *} & (0.083) & 0.068 & (0.083) & -0.017 & (0.071) & -0.035 & (0.086)\end{array}$


Any social activities * female

Yrs of electricity avail * female

Mountainous region * female

Yrs of commune * female

Big surname * female

R yes, Community yes * female

R no, Community no * female

Prefecture Dummies

YES

Observation

R-squared

10,946

0.419
0.003

$0.013^{* * *}$

$(0.072)$

(0.004)

0.009

$(0.096)$

$-0.006$

(0.007)

$0.100 \quad(0.090)$

$0.231 *$

(0.124)

YES

10,946

0.420
0.042

$-0.001$

$-0.024$

$-0.001$

0.086

0.037

YES

YES

10,975

0.281
$(0.063)$

$(0.004)$

Standard errors in parentheses.

$* * * \mathrm{p}<0.01,{ }^{* *} \mathrm{p}<0.05,{ }^{*} \mathrm{p}<0.1$. 
Table 7. OLS Analysis Adding Economic and Environmental Development

\begin{tabular}{|c|c|c|c|c|c|c|c|c|}
\hline \multirow{2}{*}{ Independent Variables } & & \multicolumn{3}{|c|}{ Mental Intactness } & \multicolumn{4}{|c|}{ Episodic Memory } \\
\hline & & \multirow[t]{2}{*}{ (1) } & \multicolumn{2}{|c|}{ (2) } & \multicolumn{2}{|c|}{ (3) } & \multicolumn{2}{|c|}{ (4) } \\
\hline Demographics & & & & & & & & \\
\hline Age - 45 & $0.021 * * *$ & $(0.006)$ & $0.021 * * *$ & $(0.006)$ & -0.001 & $(0.005)$ & -0.001 & $(0.005)$ \\
\hline (Age - 45) squared & $-0.001 * * *$ & $(0.000)$ & $-0.001^{* * *}$ & $(0.000)$ & $-0.001^{* * *}$ & $(0.000)$ & $-0.001 * * *$ & $(0.000)$ \\
\hline Female & $-1.351 * *$ & $(0.601)$ & $-1.303 * *$ & $(0.615)$ & -0.682 & $(0.571)$ & -0.740 & $(0.580)$ \\
\hline Urban & $0.208^{* * *}$ & $(0.050)$ & $0.212^{* * *}$ & $(0.050)$ & $0.131^{* * *}$ & $(0.044)$ & $0.127 * * *$ & $(0.043)$ \\
\hline Log Height & $4.533 * * *$ & $(0.554)$ & $4.517^{* * *}$ & $(0.556)$ & $0.932 * *$ & $(0.434)$ & $0.958^{* *}$ & $(0.434)$ \\
\hline \multicolumn{9}{|l|}{ SES } \\
\hline \multicolumn{9}{|l|}{ Education(illiterate omitted) } \\
\hline Sishu/home school and below & $1.398 * * *$ & $(0.065)$ & $1.394 * * *$ & $(0.065)$ & $0.402 * * *$ & $(0.049)$ & $0.400 * * *$ & $(0.049)$ \\
\hline Elementary school & $2.118^{* * *}$ & $(0.061)$ & $2.116^{* * *}$ & $(0.062)$ & $0.754 * * *$ & $(0.050)$ & $0.752^{* * *}$ & $(0.050)$ \\
\hline Middle school & $2.571 * * *$ & $(0.064)$ & $2.569 * * *$ & $(0.064)$ & $1.204 * * *$ & $(0.055)$ & $1.205^{* * *}$ & $(0.055)$ \\
\hline High school and above & $2.843^{* * *}$ & $(0.071)$ & $2.840 * * *$ & $(0.071)$ & $1.649 * * *$ & $(0.068)$ & $1.649 * * *$ & $(0.068)$ \\
\hline Log household PCE & $0.170 * * *$ & $(0.037)$ & $0.172 * * *$ & $(0.038)$ & $0.151^{* * *}$ & $(0.034)$ & $0.152^{* * *}$ & $(0.034)$ \\
\hline Community log PCE & $0.169 * *$ & $(0.068)$ & $0.192 * * *$ & $(0.069)$ & -0.025 & $(0.065)$ & -0.023 & $(0.066)$ \\
\hline Community log PCE*female & $0.182^{* *}$ & $(0.086)$ & $0.152 *$ & $(0.089)$ & 0.081 & $(0.081)$ & 0.087 & $(0.084)$ \\
\hline Log household PCE*female & -0.043 & $(0.055)$ & -0.046 & $(0.055)$ & 0.018 & $(0.047)$ & 0.017 & $(0.047)$ \\
\hline \multicolumn{9}{|l|}{ Prefecture variables } \\
\hline $\begin{array}{l}\text { Growth rate of } \\
\text { Green coverage ratio 1997-2003 }\end{array}$ & $0.001 * * *$ & $(0.000)$ & $0.001 * *$ & $(0.000)$ & $0.001^{* * *}$ & $(0.000)$ & 0.000 & $(0.000)$ \\
\hline $\begin{array}{l}\text { Growth rate of wage per capita } \\
\text { 1996-2007 }\end{array}$ & $0.015 * * *$ & $(0.003)$ & $0.015^{* * *}$ & $(0.003)$ & $-0.006^{* *}$ & $(0.003)$ & -0.004 & $(0.003)$ \\
\hline Green coverage ratio 1996 & $0.021 * * *$ & $(0.003)$ & $0.022 * * *$ & $(0.004)$ & 0.002 & $(0.003)$ & 0.005 & $(0.003)$ \\
\hline Wage per capita 1995 (thousand) & $1.159 * * *$ & $(0.281)$ & $0.689 * *$ & $(0.305)$ & 0.326 & $(0.250)$ & 0.178 & $(0.286)$ \\
\hline $\begin{array}{l}\text { Growth rate of } \\
\text { Green coverage ratio } \\
1997-2003 * \text { female }\end{array}$ & & & 0.001 & $(0.001)$ & & & $0.001 *$ & $(0.000)$ \\
\hline Growth rate of wage per capita & & & -0.001 & $(0.004)$ & & & -0.004 & $(0.003)$ \\
\hline
\end{tabular}


1996-2007* female

Green coverage ratio 1996 *

female

Wage per capita 1995 (thousand) *

female

Province Dummies

YES

Observation

R-squared

11,28

Standard errors in parentheses

$* * * \mathrm{p}<0.01, * * \mathrm{p}<0.05, * \mathrm{p}<0.1$.

$\begin{array}{lllll}0.001 & (0.005) & & -0.008 * & (0.004) \\ 0.486 & (0.330) & & 0.428 & (0.314) \\ \text { YES } & & \text { YES } & \\ 11,281 & & \text { YES } & \\ 0.380 & & 11,315 & 11,315 & \\ & & 0.205 & 0.205 & \end{array}$

0.381

11,315

0.205 